\title{
Formation of blisters in thin metal films on lithium niobate implanted by $\mathrm{keV} \mathrm{Ar}^{+}$ions
}

\author{
V.O. Lysiuk ${ }^{1,2}$, N.L. Moskalenko ${ }^{1}$, V.S. Staschuk ${ }^{2}$, M.I. Kluy ${ }^{1}$, \\ O.V. Vakulenko ${ }^{2}$, I.G. Androsyuk ${ }^{1}$, M.A. Surmach ${ }^{1}$, V.I. Pogoda ${ }^{1}$ \\ ${ }^{1} V$. Lashkaryov Institute of Semiconductor Physics, NAS of Ukraine \\ 41, prospect Nauky, 03028 Kyiv, Ukraine; phone: +380(44) 525-6205; fax: +380(44) 525-5430 \\ ${ }^{2}$ Taras Shevchenko Kyiv National University, D epartment of Physics, \\ 2, bld.1, prospect Glushkova, 03022 Kyiv, Ukraine
}

\begin{abstract}
Bubble-like and crater-like blisters were observed at the boundaries of the structures "thin Ni film-lithium niobate" and "thin Pd film-lithium tantalate" implanted by $\mathrm{Ar}^{+}$ions. Analyses of these systems by AFM and SEM have shown that ion implantation essentially modifies near-surface structures with changing their optical, electrical and mechanical properties. Differences in the optical properties and surface structure between implanted and non-implanted systems are observed and explained by different properties of materials, widening interface "film-substrate" as well as by other known effects and phenomena. Enhanced adhesion of these films to substrate, nonselective spectral response is a base for effective and perspective application of the systems in development of high-sensitive pyroelectric detectors with a wide spectral range and high optical damage threshold.
\end{abstract}

Keywords: lithium niobate, ion implantation, thin films, pyroelectric photodetectors.

Manuscript received 28.05.09; accepted for publication 22.10.09; published online 30.12.09.

\section{Introduction}

Ferroelectrics lithium niobate and lithium tantalate are widely used in optoelectronics and laser physics [1] because of their unique electrooptical, acoustical, piezoelectric, pyroelectric and nonlinear optical properties. Both these pyroelectric crystals have a high Courie temperature, excellent chemical and mechanical stability, and high damage threshold, what is very important for high-precision measurements of power laser radiation where high stability, durability and radiation stability are necessary [2].

Deposition of thin absorbing films on pyroelectrics allows to increase sensitivity of systems thin film pyroelectric. This is a necessary requirement for production of high-sensitive pyroeloectric detectors.

Characteristics of commercial pyroelectric detectors don't satisfy requirements of high radiation stability, sensitivity and low time constant. This is necessary for excluding the possibility of absorbing layer damage by laser radiation, if the radiation power exceeds its own critical point.

Such high-effective absorbing materials as golden black, Ni-based and other thin metal films cannot represent necessary radiation stability without ion implantation as caused by low adhesion between these thin films and substrate.

Processes that occur during ion implantation are not completely investigated. But they allow to modify surface, near-surface structure and interface filmsubstrate, change optical, mechanical and electrical characteristics of materials [3]. That is why, it is necessary to investigate the influence of ion implantation on optical properties of thin metal film on lithium niobate (or lithium tantalate) as well as to compare experimental results with the theoretically calculated ones, with the purpose to find optimal materials and technology for production of the system thin metal film - pyroelectric with advanced optical, mechanical and electrical properties [4].

For this purpose, there are the following tasks to be solved:

to determine optimal absorbing film properties (material, thicknesses, deposition method, processing methods etc.), calculating appropriate ions energy and dose for making maximal distribution of ion stopping profile on the interface film - substrate; to investigate the influence of ion implantation on optical properties (reflectance and absorption) of the samples in the wide wavelength range $(0.25-15 \mu \mathrm{m})$; to investigate the 
surface structure of the systems and compare with existing models; to analyze and determine optical characteristics of the developed pyroelectric photodetector based on the system thin metal film pyroelectric and compare with the existing ones [5].

\section{Experimental}

To create and optimize technology of metal film deposition on lithium niobate and lithium tantalate substrates, the main tasks are as follows: maximization of adhesion of metal films to substrate, deposition of stable to degradation films with the highest possible absorption and the lowest value of time constant of produced sample $[6,7]$. Optimal technological regimes were determined for metal film deposition and further processing (thermal annealing, ion implantation, etc.).

As a substrate, slices of monocrystalline lithium niobate with the thickness close to $100 \mu \mathrm{m}$ and normal orientation of the polarization vector as to the sample area. Ni, Mo and Pd were used for deposition. The films were deposited up to thicknesses of 15, 20, 30 and $40 \mathrm{~nm}$. The films with the thickness less than $15 \mathrm{~nm}$ possessed an island-like structure and were not selected for investigations. The films with thicknesses over $50 \mathrm{~nm}$ did not allow penetration of radiation to the substrate through them. That is why the samples with only mentioned thicknesses were chosen for investigations.

All the films (Ni, Mo, Pd) were deposited by the ion-plasma method in Ar atmosphere with the pressure approximately $0.5 \mathrm{mPa}$.

To determine optimal regimes of $\mathrm{Ni}, \mathrm{Mo}$ and $\mathrm{Pd}$ film deposition with necessary characteristics, such as resistance and transmission coefficient, series of samples were produced at various substrate temperatures (70$320^{\circ} \mathrm{C}$ ). As a result, the optimal regime that gave maximal film homogeneity as selected for production of samples.

To realize the ion implantation method, $\mathrm{Ar}^{+}$ions were chosen. Ion implantation with $\mathrm{Ar}^{+}$ions was made using Vesuviy 2/450 implanter at the ion current value $j_{i}=2-3 \mathrm{~A} / \mathrm{cm}^{2}$ at the pressure $0.5 \mathrm{mPa}$, varying the energy of ions from 50 up to $150 \mathrm{keV}$ and ion dose from $5 \cdot 10^{15}$ up to $2 \cdot 10^{16} \mathrm{~cm}^{-2}$. Determination of the optimal ion energy and dose were carried out using the MonteCarlo method based on calculation of ions and recoil atoms stopping profiles in the systems thin metal films lithium niobate (lithium tantalate).

During ion implantation with energies about $100 \mathrm{keV}$, the following processes occur: ions, accelerated to the energy $E$, collide with atoms of substrate and transfer a part of their kinetic energy, decelerate, change its direction from the initial one, but continue their motion to sample's depth, and collide with new atoms again. The atoms that obtain a partial energy from accelerated ions start its motion and after $N$ new collisions decelerate and, finally, stop [8]. Owing to $N$ new atoms and the obtained energy, new collisions occur. As a result, cascade of recoil atoms that move in the same direction with the implanted ion and, finally stops. To determine the distribution function for ions and recoil atoms as depending on the ion type and its energy, the Monte-Carlo method have been used. Using the computer modelling, ions and recoil atom distributions for Ni, Mo and Pd films of 20, 40 and $60 \mathrm{~nm}$ thicknesses on the lithium niobate substrate $100 \mu \mathrm{m}$ thick were calculated.

Fig. 1 represents the ion stopping profile in the thin $\mathrm{Ni}$ film on lithium niobate for the energy of ions 50, 100 and $150 \mathrm{keV}$. It is shown that maximum number of ions accelerated to $50 \mathrm{keV}$ stops at $20 \mathrm{~nm}$ from the sample surface, exactly where the interface film-substrate is located, and for the energy of ions 100 and $150 \mathrm{keV}$ - at the distances 40 and $60 \mathrm{~nm}$, accordingly. So, for the mentioned sample $50 \mathrm{keV}$ is the optimal ion energy for the most effective intermixing atoms of film and substrate at their interface.

Fig. 2 represents the distribution of ions for the systems thin Pd film - lithium niobate and thin Mo film - lithium niobate (film thickness of which is $40 \mathrm{~nm}$ ) for ion energies 50, 100 and $150 \mathrm{keV}$. As seen, the mentioned profiles have small differences, and what is important - the peaks are located at the same positions. In comparison with Fig. 1, the ion peak that corresponds to the ion energy $150 \mathrm{keV}$ shifts inside the sample bulk to the value $d=80 \mathrm{~nm}$. The ion peaks that correspond to the ion energies 50 and $100 \mathrm{keV}$ have the same locations: $d=20$ and $d=40 \mathrm{~nm}$, accordingly. MonteCarlo method calculations have shown that Ni, Mo or Pd films $40 \mathrm{~nm}$ thick deposited on lithium niobate substrate should be implanted by $\mathrm{Ar}^{+}$ions with energies close to $100 \mathrm{keV}$ for the maximal effect of increased adhesion. In this case, the maximal number of implanted ions will stop exactly at the interface film - substrate.

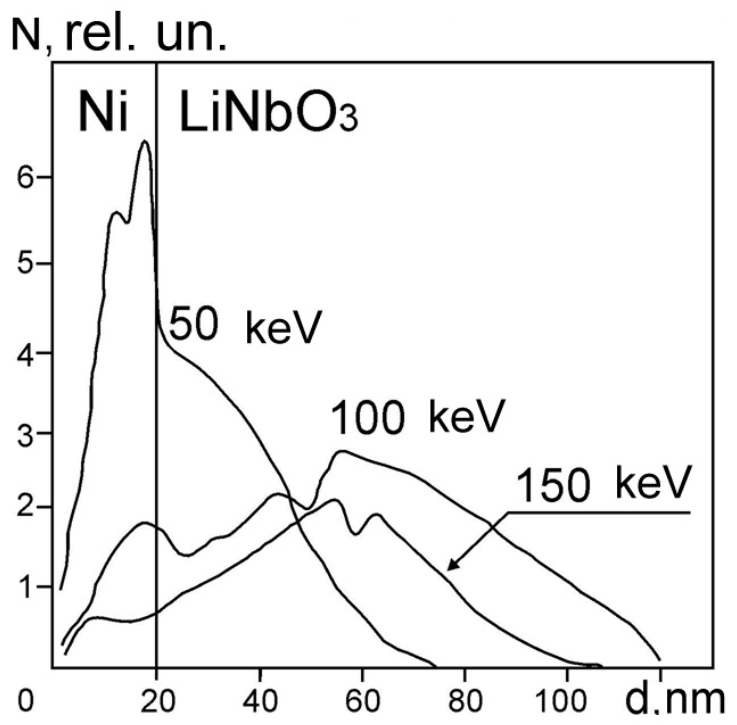

Fig. 1. Distribution of $\mathrm{Ar}^{+}$ions with energies of 50,100 and $150 \mathrm{keV}$ in the system thin Ni film $(20 \mathrm{~nm})$ - lithium niobate. 
$\mathrm{N}$, rel. un.

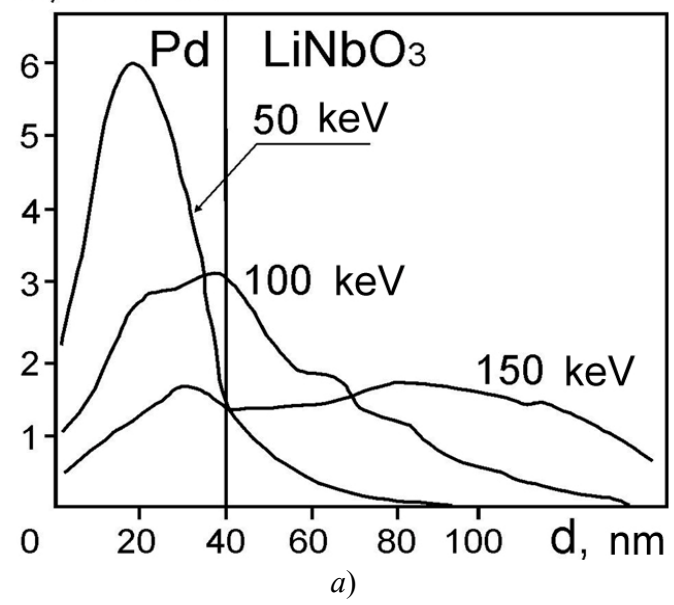

$\mathrm{N}$, rel. un.

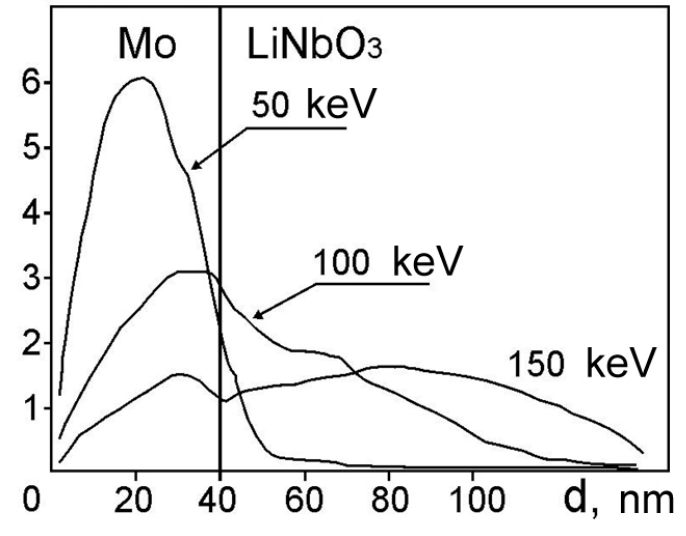

b)

Fig. 2. Distribution of $\mathrm{Ar}^{+}$ions with energies of 50,100 and $150 \mathrm{keV}$ in the system thin Pd film (40 nm) - lithium niobate (a) and thin Mo film (40 nm) - lithium niobate (b).

\section{Results and discussion}

Investigation of the surface structure of nonimplanted and implanted by $\mathrm{Ar}^{+}$ions thin metal films on pyroelectrics have been made using electron microscopy and atomic force microscopy. It is shown (Fig. 3) that before ion implantation the surfaces of $\mathrm{Ni}$, Mo and Pd films on lithium niobate were smooth without any structures, except single defects created at film deposition.

There are no sufficient differences between microrelief of nonimplanted systems $\mathrm{Ni}-\mathrm{LiNbO}_{3}, \mathrm{Mo}-\mathrm{LiNbO}_{3}$ and $\mathrm{Pd}-\mathrm{LiNbO}_{3}$ observed, and parameter $r_{\max }$ of every sample is less than $10 \mathrm{~nm}$.

The surface state of the system thin metal film lithium niobate implanted by $\mathrm{Ar}^{+}$ions is strongly changed after ion implantation and different for the samples with $\mathrm{Ni}$, Mo and Pd films.

We identified that ion implantation stimulates appearance of blisters on the surface of $\mathrm{Ni}-\mathrm{LiNbO}_{3}$ (Fig. 4). Geometry of blisters is similar to bubbles with the intrinsic diameter from $50 \mathrm{~nm}$ to $2 \mu \mathrm{m}$, and their maximal height is $82 \mathrm{~nm}$.

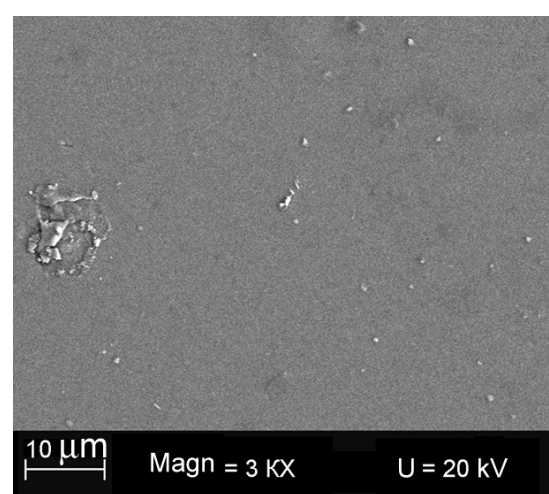

a)

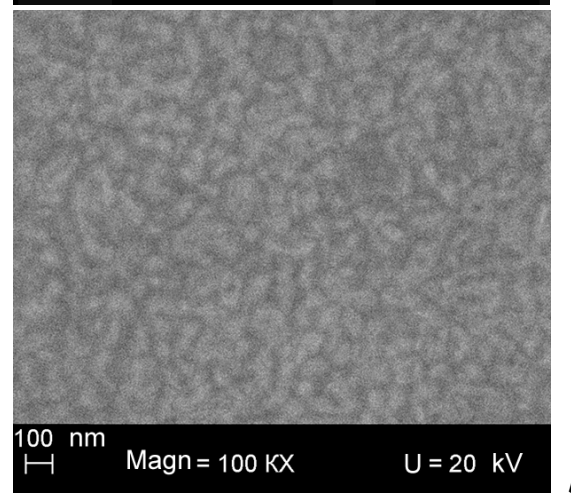

b)

Fig. 3. Electron microscopy images of deposited $\mathrm{Ni}$ films $(40 \mathrm{~nm})$ on lithium niobate with magnification of $3 \cdot 10^{3}$ (a) and $10^{5}$ (b) obtained by Zeiss Ultra 55 Electron Microscope.

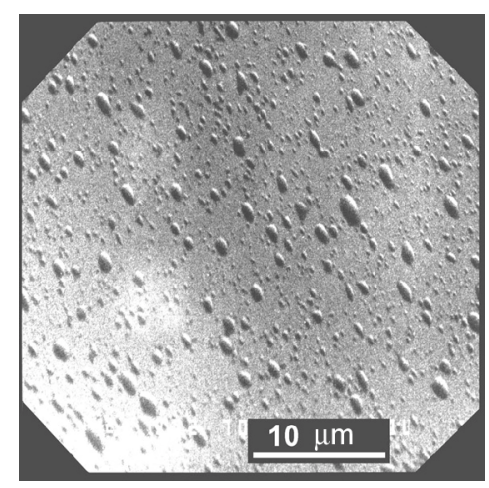

a)

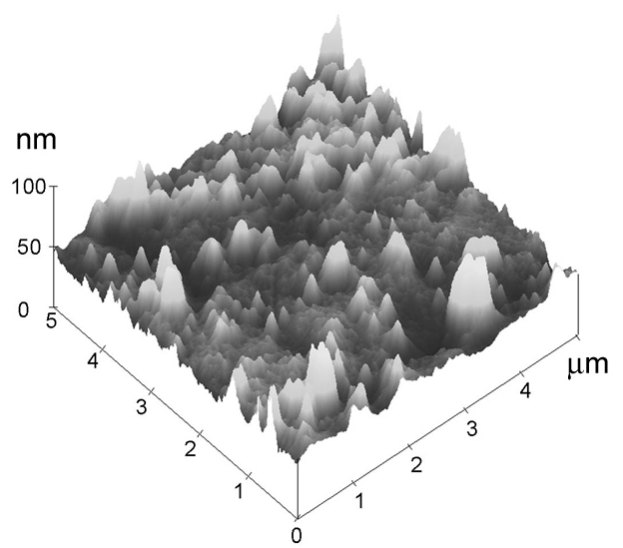

b)

Fig. 4. Typical micro-relief of the Ni film $(40 \mathrm{~nm})$ on lithium niobate implanted by $\mathrm{Ar}^{+}$ions with the energies $100 \mathrm{keV}$ and dose $10^{16} \mathrm{~cm}^{-2}$, obtained by Electron Microscope DGSM-35 (a) and Atomic Force Microscope (b). 
Blisters appeared not immediately after ion implantation, but after thermal annealing. The mechanism of stimulation of blister formation is exit of argon gas outside from the film bulk during system relaxation. This result is confirmed by qualitative X-ray investigations that have shown absence of argon inside the samples.

Surface structure investigations for thin Mo film lithium niobate have shown that ion implantation stimulates formation of layered structure in Mo film as a result of partial exfoliation of Mo under action of highenergy $\mathrm{Ar}^{+}$ions. The obtained maximal height of the structures $r_{\max }$ is $20 \mathrm{~nm}$, what is sufficiently less than that for thin $\mathrm{Ni}$ films on lithium niobate.

Dimensions of craters vary from $200 \mathrm{~nm}$ to $10 \mu \mathrm{m}$, and their height is limited by $2 \mu \mathrm{m}$. Mechanism of crater formation in the systems thin Pd film - lithium niobate starts from bubble-like blisters like to that for Ni film on lithium niobate. Bubble damages are created due to a low hardness limit and surface tension coefficient of $\mathrm{Pd}$ in comparison with those of $\mathrm{Ni}$ and Mo.

$\mathrm{X}$-ray analyses have shown amorphyzation of thin metal film as well as subsurface layer of lithium niobate.

Modification of the surface structure of the samples should change their optical properties.

Transmission spectra of non-implanted systems Ni$\mathrm{LiNbO}_{3}, \mathrm{Mo}-\mathrm{LiNbO}_{3}$ and $\mathrm{Pd}-\mathrm{LiNbO}_{3}$ measured in the wide spectral range $(0.2-15 \mu \mathrm{m})$ are similar. The increase in the metal film thickness causes a decrease in transmission. Optical properties of the system in the shortwave (UV and visible) range is mainly caused by film properties, and in the infrared mainly by substrate properties.

The most interesting micro-relief images were obtained for thin Pd films on lithium niobate implanted with $\mathrm{Ar}^{+}$ions.

By contrast to $\mathrm{Ni}$ and Mo films, in this system ion implantation causes formation of craters.

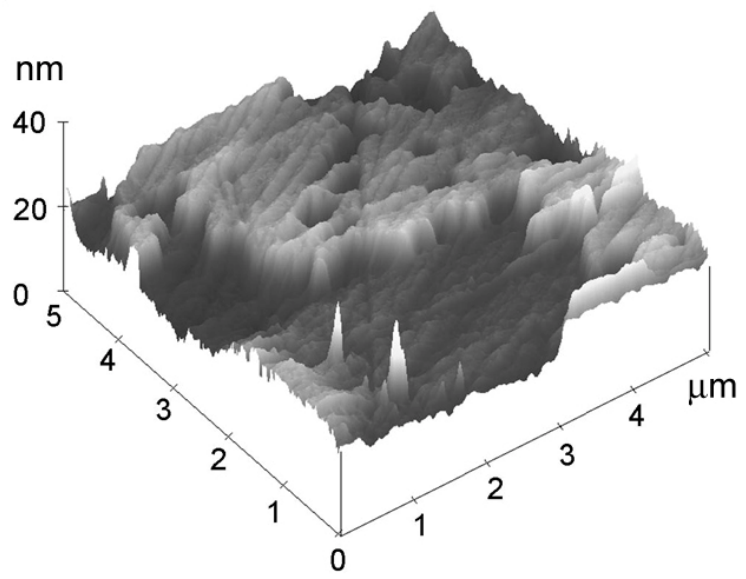

Fig. 5. Micro-relief of Mo film (40 nm) on lithium niobate implanted with $\mathrm{Ar}^{+}$ions with the energy $100 \mathrm{keV}$ and dose $10^{16} \mathrm{~cm}^{-2}$ obtained using AFM.

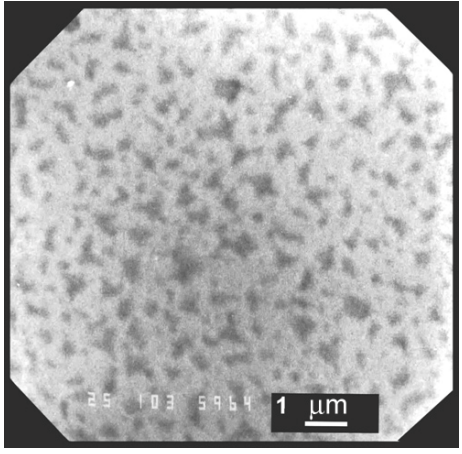

a)

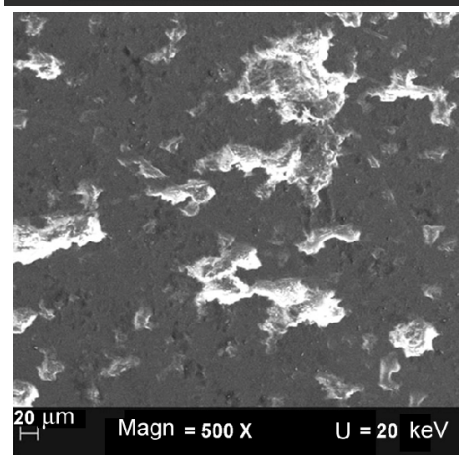

b)

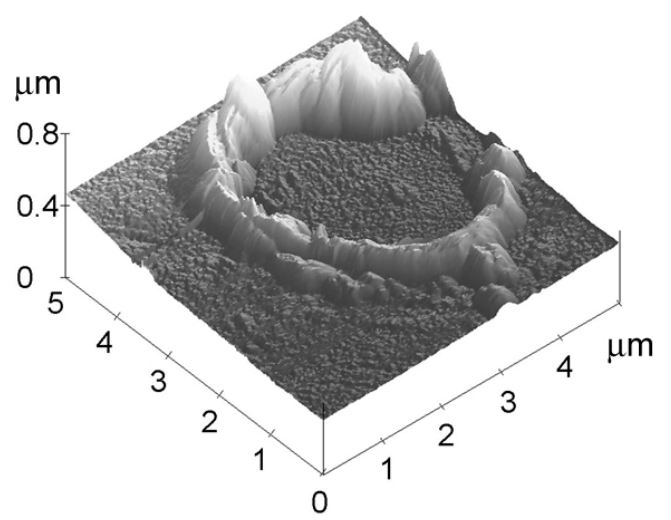

c)

Fig. 6. Micro-relief of thin Pd film $(40 \mathrm{~nm})$ on lithium niobate implanted by $\mathrm{Ar}^{+}$ions with the energy $100 \mathrm{keV}$ and dose $10^{16} \mathrm{~cm}^{-2}$ obtained using electron microscopes DGSM-35 (a), Zeiss Ultra 55 (b) and AFM (c).

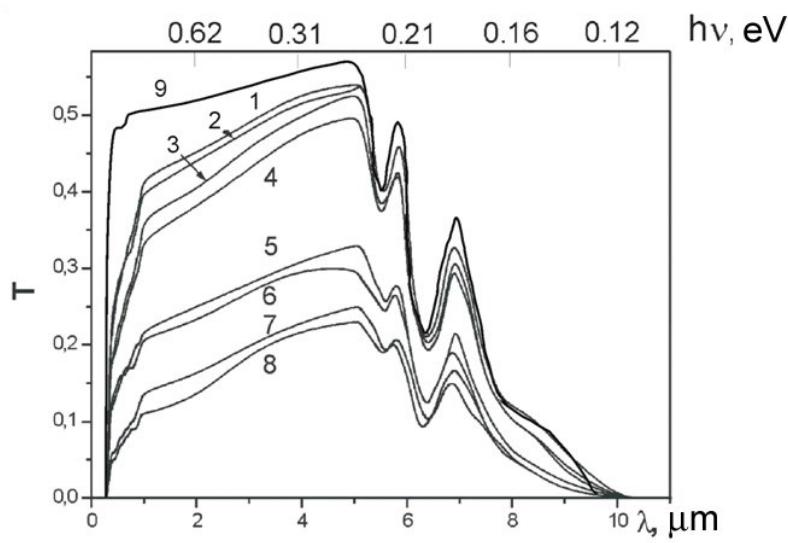

Fig. 7. Transmission spectra $T(\lambda)$ of thin Ni film on lithium niobate with the Ni film thicknesses $15(1,2), 20(3,4), 30$ $(5,6)$ and $40 \mathrm{~nm}(7,8)$ before $(2,4,6,8)$ and after ion implantation $(1,3,5,7)$ in comparison with lithium niobate single crystal ( 9 ). 

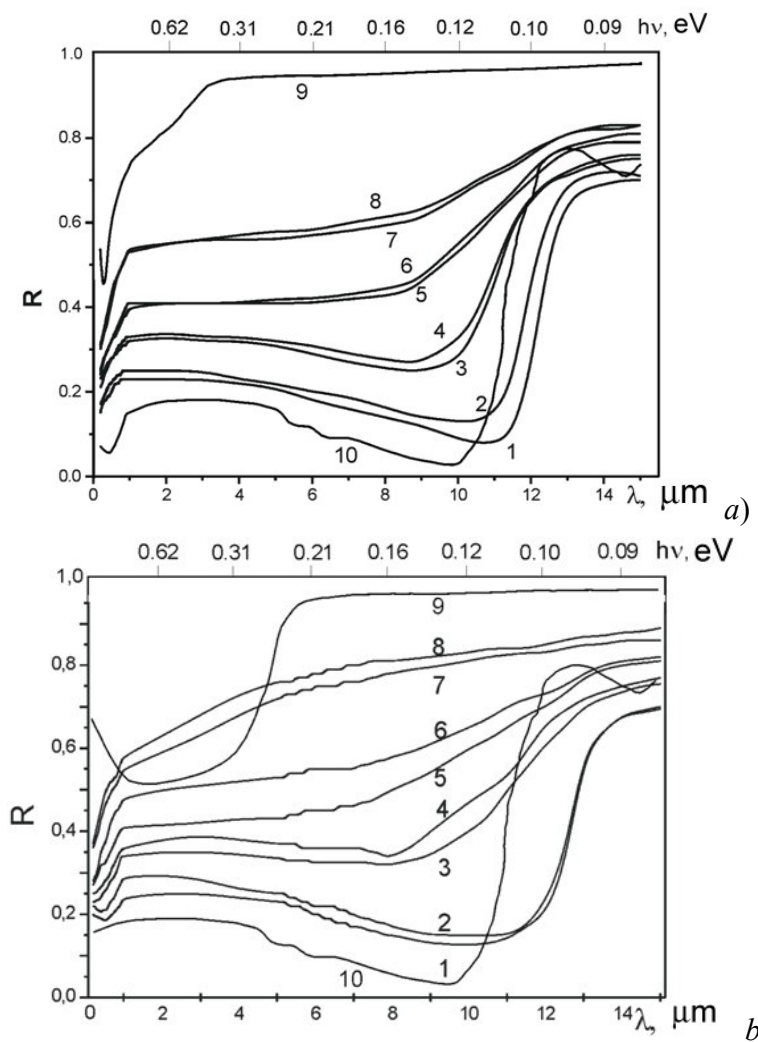

Fig. 8. Reflectance spectra of thin Ni film - lithium niobate (a), thin Mo film - lithium niobate (b) with the film thicknesses 15 $(1,2), 20(3,4), 30(5,6)$ and $40 \mathrm{~nm}(7,8)$ before $(2,4,6,8)$ and after ion implantation $(1,3,5,7)$ in comparison with bulk $\mathrm{Ni}$ and Mo polycrystals (9) and monocrystalline lithium niobate (10).

It has been shown that two absorption bands are observed near $\lambda=5.5$ and $6.2 \mu \mathrm{m}$, which can be related with presence of $\mathrm{H}-\mathrm{O}-\mathrm{H}$ in $\mathrm{LiNbO}_{3}$ and by oscillation of $\mathrm{H}_{2} \mathrm{O}$ molecular complexes and other inclusions. In the spectral range near $\lambda=10.5 \mu \mathrm{m}$, an intensive band that causes a decrease in transmission is observed. This band is related with valent bridge oscillations of oxygen in the octahedron $\mathrm{NbO}_{6}$. These oscillations are fundamental phonons of lithium niobate that have almost the same frequencies as lithium tantalate as a result of the same molecular structure - the same point group symmetry $(3 \mathrm{~m})$ and transition group symmetry (R3c).

As shown in Fig. 7, ion implantation causes rise of transmission of $\mathrm{Ni}-\mathrm{LiNbO}_{3}$ in visible and near infrared $(0.4-6.0 \mu \mathrm{m})$, what is the result of widening the interface film-substrate and disorder in the near-surface structure of the metal film.

Results of spectral investigations of reflectance spectra in the wide spectral range $(\lambda=0.25-15 \mu \mathrm{m})$ have shown that the reflection coefficients for $\mathrm{Ni}-\mathrm{LiNbO}_{3}$ and $\mathrm{Mo}-\mathrm{LiNbO}_{3}$ decrease in all the spectral range after ion implantation [9, 10]. The maximal differrence between nonimplanted and implanted samples is obtained for the $\mathrm{Ni}$ film with the thickness $15 \mathrm{~nm}$ and Mo film with the thickness $30 \mathrm{~nm}$. Comparing the optical properties and surface structure of the mentioned samples, it is possible to conclude that decrease of reflectance spectra may be related with creation of a rough surface as a result of blister formation and decrease of heterogeneity of the interface film-substrate. Calculations of reflectance spectra for the Ni surface as dependent on the roughness have shown that light scattering on blisters is not the only factor that provides the decrease in the reflection coefficient of the systems.

Reflectance spectra of ion implanted thin Pd films on lithium niobate strongly differ from those of ion implanted thin $\mathrm{Ni}$ or Mo films on lithium niobate. Ion implantation causes a decrease in reflectance spectra for thin Mo or Pd films on lithium niobate.

Differences between nonimplanted and implanted systems are sufficiently higher for maximal film thicknesses in comparison with their less value. As a result of ion implantation of $\mathrm{Pd}$ films (30 and $40 \mathrm{~nm}$ ) on lithium niobate, the reflection coefficient is not selective (i.e. independent from the wavelength) in the wide spectral range $(1-15 \mu \mathrm{m})$. Loosing selectivity may be related with the crater-like structure arising after ion implantation, what causes an increased absorption and appropriate decrease in the reflection coefficient of the systems, what is also confirmed theoretically, if taking into account the roughness of implanted Pd film.

Absorption spectra was obtained using relation $A(\lambda)=1-R(\lambda)-T(\lambda)$ within the spectral range $(\lambda=0.25$ $-15 \mu \mathrm{m})$. It is important result that ion implantation causes an increased absorption of the samples in the infrared (Figs 8 and 9) as a result of the following factors: surface microrelief and its roughness changes, light scattering on blisters and absorption by craters, amorphyzation of metal film and pyroelectric subsurface layer; decrease of heterogeneity of the interface film-substrate as caused by its widening.

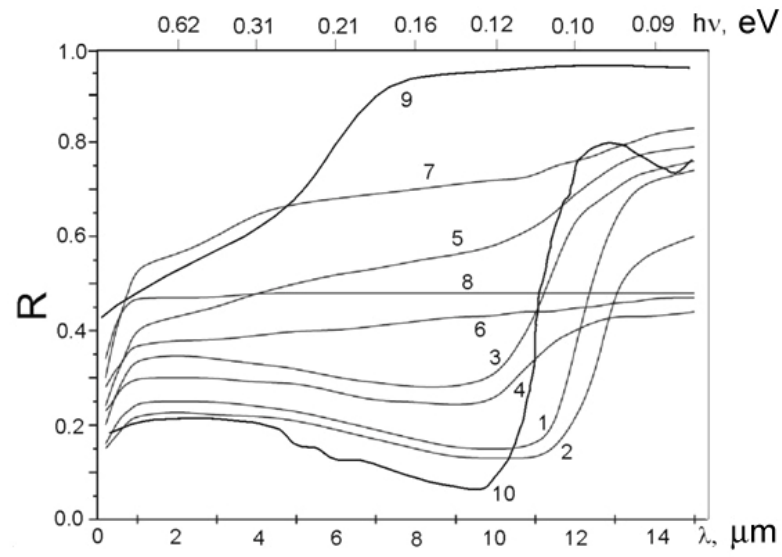

Fig. 9. Reflectance spectra of thin Pd films on lithium niobate with the Pd film thicknesses of $15(1,2), 20(3,4), 30(5,6)$ and $40 \mathrm{~nm}(7,8)$ before $(1,3,5,7)$ and after ion implantation $(2,4,6,8)$ in comparison with those of bulk polycrystalline $\mathrm{Pd}$ (9) and lithium niobate single crystal (10). 
Table 1. Characteristics of different types of pyroelectric photodetectors.

\begin{tabular}{|l|c|c|c|c|c|c|}
\hline $\begin{array}{c}\text { Type of } \\
\text { photodetector }\end{array}$ & $\begin{array}{c}\text { Area of } \\
\text { sensitive } \\
\text { element } \\
\left(\mathrm{mm}^{2}\right)\end{array}$ & $\begin{array}{c}\text { Sensitivity } \\
(\mathrm{V} / \mathrm{W})\end{array}$ & $\begin{array}{c}\text { Effective } \\
\text { noise voltage } \\
\left(\mathrm{V} \cdot \mathrm{Hz}^{-1 / 2}\right)\end{array}$ & $\begin{array}{c}\text { Detectivity } \\
\left(\mathrm{cm} \cdot \mathrm{Hz}^{1 / 2} / \mathrm{W}\right)\end{array}$ & $\begin{array}{c}\text { Time } \\
\text { constant } \\
(\mu \mathrm{s})\end{array}$ & $\begin{array}{c}\text { Damage } \\
\text { threshold } \\
(\mathrm{W})\end{array}$ \\
\hline $\begin{array}{l}\text { LTA G2 PC } \\
\text { (Dias) }\end{array}$ & 4 & $>200$ & $<10^{-7}$ & $>3.7 \cdot 10^{8}$ & - & - \\
\hline $\begin{array}{l}\text { LTSI Q3 } \\
\text { (Dias) }\end{array}$ & 9 & $>180$ & $<6 \cdot 10^{-8}$ & $10^{9}$ & - & 0.38 \\
\hline $\begin{array}{l}\text { PY 55 } \\
\text { (Goodrich) }\end{array}$ & 9 & 845 & $2.9 \cdot 10^{-10}$ & $10^{9}$ & $<50$ & - \\
\hline $\begin{array}{l}\text { Pyroelectric, } \\
\text { coated by } \\
\text { graphene }\end{array}$ & 9 & - & - & - & - & $0.5-1.1$ \\
\hline LiNbO3 bulk & - & $3 \cdot 10^{4}$ & - & $1.2 \cdot 10^{8}$ & $5.2 \cdot 10^{3}$ & - \\
\hline Ni Bolometer & 0.76 & 11 & $10^{-6}$ & $0.87 \cdot 10^{6}$ & $22 \cdot 10^{3}$ & - \\
\hline $\begin{array}{l}\text { Ni-LiNbO } \\
\text { implanted }\end{array}$ & 8 & $3.5 \cdot 10^{3}$ & $5 \cdot 10^{-7}$ & $5.1 \cdot 10^{7}$ & 5 & 50 \\
\hline $\begin{array}{l}\text { Pd-LiNbO } \\
\text { implanted }\end{array}$ & 8 & $4.9 \cdot 10^{3}$ & $2.3 \cdot 10^{-7}$ & $1.2 \cdot 10^{8}$ & 8 & 45 \\
\hline $\begin{array}{l}\text { Pd-LiTaO } \\
\text { implanted }\end{array}$ & 8 & $5.5 \cdot 10^{3}$ & $10^{-6}$ & $2.5 \cdot 10^{8}$ & 12 & 30 \\
\hline
\end{tabular}
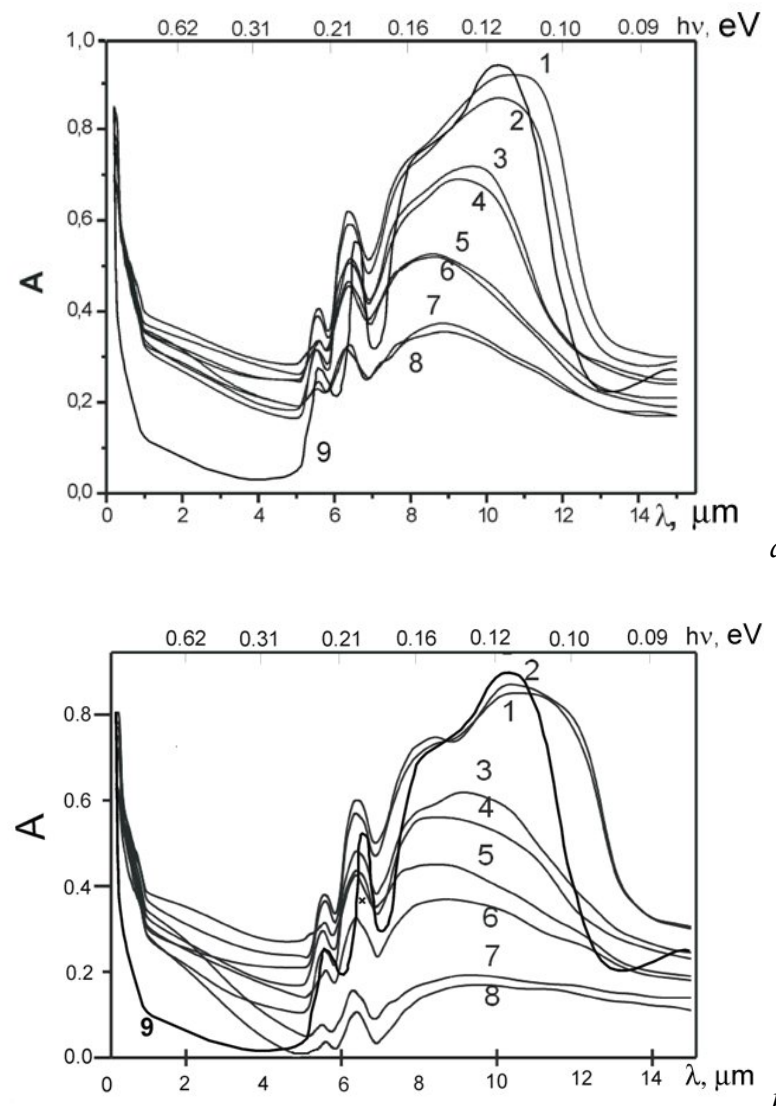

b)

Fig. 10. Absorption spectra of thin $\mathrm{Ni}(a)$ and $\mathrm{Mo}(b)$ films with the thicknesses $15(1,2), 20(3,4), 30(5,6)$, and $40 \mathrm{~nm}$ $(7,8)$ on lithium niobate before $(2,4,6,8)$ and after implantation $(1,3,5,7)$ in comparison with that of monocrystalline lithium niobate (9).

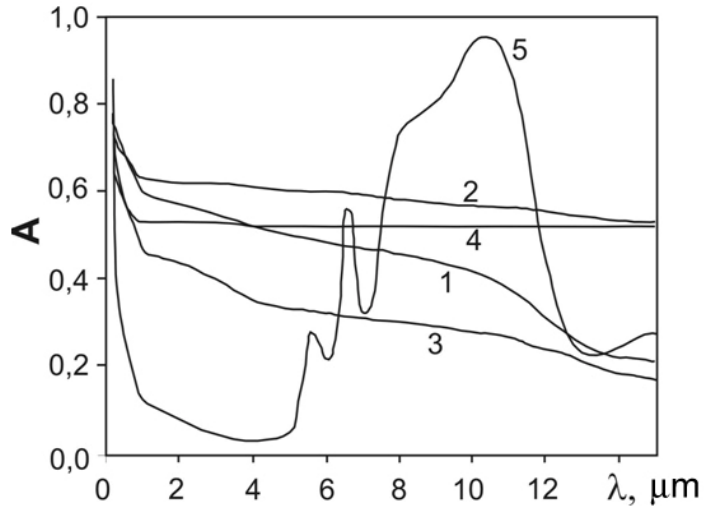

a)

Fig. 11. Absorption spectra of thin Pd film - lithium niobate with film thicknesses $30(1,2)$, and $40 \mathrm{~nm}(3,4)$ before $(1,3)$ and after ion implantation $(2,4)$ in comparison with that of monocrystalline lithium niobate (5).

Measurements and calculations of technical characteristics of pyroelectric photodetector have shown a number of advantages in comparison with existing commercial devices.

Characteristics of pyroelectric photodetectors based on the investigated systems in comparison with analogs and other thermal detectors of infrared spectroscopy are represented in Table 1. Most of characteristics of the investigated system have better values than those of analogs. And what is the most important, implanted systems thin metal film-lithium niobate have nonselective spectral response in the infrared $(\lambda=1-15 \mu \mathrm{m})$.

The obtained results have practical meaning according to the possibility of application of the systems thin metal film - lithium niobate implanted with $\mathrm{Ar}^{+}$ions in spectral optoelectronic devices owing to their characteristics and nonselective response. 


\section{Conclusions}

1. It has been shown that the ion energies of 50$150 \mathrm{keV}$ are optimal for effective structure modification in the interface film-substrate where the maximal number of ions stops.

2. It has been ascertained that blisters on the surface of $\mathrm{Ni}$ films appear in the result of tensions caused by Ar gas between film and substrate during thermal annealing. At the same conditions of ion implantation, detachment of metal slices is observed for Mo films, and craters from 1 to $15 \mu \mathrm{m}$ for Pd films on $\mathrm{LiNbO}_{3}$ that may be related with damages of bubble-like blisters in the result of a less value of surface tensions for $\mathrm{Pd}$ film than for $\mathrm{Ni}$ melt as well as their tensile strength.

3. Sharp decrease of the reflectance $R(\lambda)$ and appropriate increase of absorption $A(\lambda)$ in the systems $\mathrm{Pd}-\mathrm{LiNbO}_{3}$ and nonselective spectral response are mainly caused by the obtained surface structure, and secondary by widening the interface film-substrate as a result of ion implantation.

4. Blisters were formed as a result of exit of $\mathrm{Ar}$ out of the film bulk. Bubble-like blisters for Ni films differ from crater-like blisters for Pd films owing to different surface tension coefficients and tensile strength (both less for Pd).

5. It has been shown that decrease of reflectance and increase of absorption of the implanted systems "Pd film $40 \mathrm{~nm}-\mathrm{LiNbO}_{3}$ " and nonselectivity in the wide spectral range are caused by close values of crater dimensions and the wavelength of radiation. According to Mie theory, such structures increase light scattering forward, increasing absorption and decreasing reflection at the same time.

Development of high-effective sensors of infrared radiation based on the implanted system $\mathrm{Pd}-\mathrm{LinbO}_{3}$ is proposed according to its high sensitivity $-2.5 \cdot 10^{8} \mathrm{~V} / \mathrm{W}$, time constant - $1.6 \mu \mathrm{m}$, non-selectivity, damage threshold $-5 \cdot 10^{3} \mathrm{~W} / \mathrm{cm}^{2}$, what is competitive with industrial thermal photodetectors. This circumstance allows using the developed photodetectors in detector systems for IR radiation.

\section{References}

1. H. Chaib, T. Otto, and L.M. Eng, Electrical and optical properties of $\mathrm{LiNbO}_{3}$ single crystals at room temperature // Phys. Rev. B 67, 174109 (2003).

2. V. Caciuk, $\mathrm{Ab}$ initio zone-center phonons in $\mathrm{LiTaO}_{3}$ : Comparison to $\mathrm{LiNbO}_{3} / /$ Phys. Rev. B 64, 224303 (2001).

3. V.O. Lysiuk, L.V. Poperenko, V.S. Staschuk, and M.I. Kluy, Study of the systems thin metal film thick lithium niobate substrate implanted by $\mathrm{Ar}^{+}$ ions and its application for production of pyroelectric photodetectors, in: Smart Sensors, Actuators and MEMS, Jung-Chih Chiao, Vijay K. Varadan, and Carles Cane eds. // Proc. SPIE 5116, p. 818-827 (2003).

4. C.K. Sheen, T.C. Chow, M.L. Hu, Y.D. Juang, W.S. Tse, and S.J. Lin, Low temperature phase transition of triglicine sulfate studied by Raman scattering // Chinese J. Phys. 35, No. 6-11, p. 929934 (1997).

5. J. Novotny, B. Brezina, and J. Zelinka, Growth and characterization of TGS and DTGS single crystals doped with $\mathrm{Pt}(\mathrm{II}), \mathrm{Pt}(\mathrm{IV})$ and L-alanine // Cryst. Res. Technol. 39, No. 12, p. 1089-1098 (2004).

6. L.M.P. Pinheiro et al., Structure, morphology and composition of thin $\mathrm{Pd}$ and $\mathrm{Ni}$ films deposited by $\mathrm{dc}$ magnetron sputtering on polycrystalline $\mathrm{Ni}$ and Pd foils // J. Phys. D: Appl. Phys. 38, p. 4241-4244 (2005).

7. John Lehman, Evangelos Theocharous, George Eppeldauer, and Chris Pannell, Gold-black coatings for free standing pyroelectric detectors // Meas. Sci. Technol. 14, p. 916-922 (2003).

8. S.G. Mayr and R.S. Averback, Effect of ion bombardment on stress in thin metal films // Phys. Rev. B 68, 214105 (2003).

9. V.O. Lysyuk, L.V. Poperenko, V.S. Staschuk, Investigations of characteristics of metal film based pyroelectric detectors implanted by $\mathrm{Ar}^{+}$ions // Semiconductor Physics, Quantum Electronics and Optoelectronics, 5, No.4, p. 412-416 (2002).

10. V.O. Lysiuk, V.S. Staschuk, M.I. Kluy et al., Influence of ion implantation on the near-surface structure of thin $\mathrm{Ni}$ and $\mathrm{Pd}$ films on lithium niobate and lithium tantalite // Semiconductor Physics, Quantum Electronics and Optoelectronics 10, No.2, p. 76-80 (2007). 